\title{
Successful Blue Economy Examples With an Emphasis on International Perspectives
}

OPEN ACCESS

Edited by:

Sanae Chiba,

Japan Agency for Marine-Earth Science and Technology, Japan

Reviewed by: Cornelia E. Nauen, Mundus Maris, Belgium Athanasios Kampas, Agricultural University of Athens,

Greece

${ }^{*}$ Correspondence:

Lu Wenhai

lu-wenhai@163.com

Anja Reitz

areitz@geomar.de

Specialty section:

This article was submitted to

Ocean Engineering, Technology, and Solutions for the Blue Economy,

a section of the journal

Frontiers in Marine Science

Received: 31 October 2018 Accepted: 02 May 2019

Published: 07 June 2019

Citation:

Wenhai L, Cusack C, Baker M,

Tao W, Mingbao C, Paige K,

Xiaofan Z, Levin L, Escobar E,

Amon $D$, Yue $Y$, Reitz $A$, Neves AAS,

O'Rourke E, Mannarini G, Pearlman J,

Tinker J, Horsburgh KJ, Lehodey $P$,

Pouliquen S, Dale T, Peng Z and

Yufeng Y (2019) Successful Blue

Economy Examples With an

Emphasis on International

Perspectives. Front. Mar. Sci. 6:261.

doi: 10.3389/fmars.2019.00261

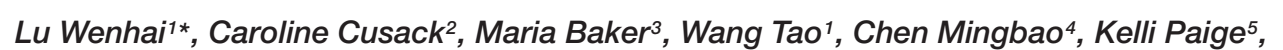
Zhang Xiaofan', Lisa Levin ${ }^{7}$, Elva Escobar', Diva Amon ${ }^{9}$, Yin Yue ${ }^{1}$, Anja Reitz ${ }^{10 *}$, Antonio Augusto Sepp Neves ${ }^{11}$, Eleanor O'Rourke' ${ }^{2}$, Gianandrea Mannarini'12, Jay Pearlman ${ }^{13}$, Jonathan Tinker ${ }^{14}$, Kevin J. Horsburgh ${ }^{15}$, Patrick Lehodey ${ }^{16}$, Sylvie Pouliquen ${ }^{17}$, Trine Dale ${ }^{18}$, Zhao Peng ${ }^{1}$ and Yang Yufeng ${ }^{19}$

${ }^{1}$ National Marine Data and Information Service, Tianjin, China, ${ }^{2}$ Marine Institute, Galway, Ireland, ${ }^{3}$ National Oceanography Centre, University of Southampton, Southampton, United Kingdom, ${ }^{4}$ Marine Economics Research Center, Sun Yat-sen University, Guangzhou, China, ${ }^{5}$ Great Lakes Observing System, Ann Arbor, MI, United States, ${ }^{6}$ College of Economics, Ocean University of China, Qingdao, China, ${ }^{7}$ Integrative Oceanography Division and Center for Marine Biodiversity and Conservation, Scripps Institution of Oceanography, University of California, San Diego, La Jolla, CA, United States, ${ }^{8}$ Institute of Marine Sciences and Limnology, National Autonomous University of Mexico, Cuernavaca, Mexico, ${ }^{9}$ Natural History Museum, London, United Kingdom, ${ }^{10}$ GEOMAR-Helmholtz Centre for Ocean Research Kiel, Kiel, Germany, ${ }^{11}$ Department of Physics and Astronomy, University of Bologna, Bologna, Italy, ${ }^{12}$ Centro Euro-Mediterraneo sui Cambiamenti Climatici, Lecce, Italy, ${ }^{13}$ Institute of Electrical and Electronics Engineers, Paris, France, ${ }^{14}$ Met Office, Exeter, United Kingdom, ${ }^{15}$ National Oceanography Centre, Natural Environment Research Council, Liverpool, United Kingdom, ${ }^{16}$ Collecte Localisation Satellites, Marine Ecosystem Modeling Team, Toulouse, France, ${ }^{17}$ Institut Francais de Recherche pour I'Exploitation de la MER, Brest, France, ${ }^{18}$ Norwegian Institute for Water Research, Oslo, Norway, ${ }^{19}$ Institute of Aquatic Biology, Jinan University, Guangzhou, China

Careful definition and illustrative case studies are fundamental work in developing a Blue Economy. As blue research expands with the world increasingly understanding its importance, policy makers and research institutions worldwide concerned with ocean and coastal regions are demanding further and improved analysis of the Blue Economy. Particularly, in terms of the management connotation, data access, monitoring, and product development, countries are making decisions according to their own needs. As a consequence of this lack of consensus, further dialogue including this cases analysis of the blue economy is even more necessary. This paper consists of four chapters: (I) Understanding the concept of Blue Economy, (II) Defining Blue economy theoretical cases, (III) Introducing Blue economy application cases and (IV) Providing an outlook for the future. Chapters (II) and (III) summarizes all the case studies into nine aspects, each aiming to represent different aspects of the blue economy. This paper is a result of knowledge and experience collected from across the global ocean observing community, and is only made possible with encouragement, support and help of all members. Despite the blue economy being a relatively new concept, we have demonstrated our promising exploration in a number of areas. We put forward proposals for the development of the blue economy, including shouldering global responsibilities to protect marine ecological environment, strengthening international communication and sharing development achievements, and promoting the establishment of global blue partnerships. However, there is clearly much room for further development in terms of the scope and depth of our collective understanding and analysis.

Keywords: blue economy, macro-economic control policies, deep ocean stewardship, science-based products, data analysis and information delivery, ecological restoration 


\section{UNDERSTANDING OF BLUE ECONOMY}

Since the 21st century, the concept of the "Blue Economy" has become increasingly popular. International society believes that blue economy covers three economic forms: economy coping with global water crisis ${ }^{1}$ (McGlade et al., 2012); innovative development economy ${ }^{2}$ (Pauli, 2009) and development of marine economy $^{3}$ (Behnam, 2012).

In the field of academic research, the research literature about blue economy mainly includes the following aspects. Kathijotes (2013) put forward the aim of Blue Economy models is to shift resources from scarcity to abundance, and to start tackling issues that cause environmental problems. Mulazzani et al. (2016) put forward the management tool based on ecosystem service framework to solve the coastal blue growth. Soma et al. (2018) proposed to achieve long-term sustainable blue growth through collaboration, inclusion and trust in the marine sector. van den Burg et al. (2019) focused on summarizing the possible boundaries of the growth of the marine industry from the spatial dimension of blue growth.

Most management research of the blue economy is based on a sustainable development perspective. Keen et al. (2018) designed a conceptual framework for blue economy can be used to assess sustainable marine management. Sarker et al. (2018) also developed a management framework of blue growth emphasizing that it requires joint efforts to promote blue growth and achieve sustainable development goals (SDGs). Howard (2018) had indepth discussion on the role of stakeholders in sustainable development. The convergence of the blue economy and marine ecosystem, ecosystem accounting is closely linked to blue growth (Häyhä and Franzese, 2014; Lillebø et al., 2017).

Blue growth concept can be traced back to sustainable development, with the increase of international communication and in-depth study of the blue economy concept, more profound connotations are emerging. Interdisciplinary and multidisciplinary research is very important when studying blue economy cases, especially one of the main challenges is how to integrate across the involved disciplines.

\section{Blue Economic Characteristics}

Specifically, blue economy presents the following attributes:

\section{Blue Economy Has a General Economy Attribute}

Australia launched Blue Well-being Initiative, recognizing that ocean-based industrial development and growth, or blue GDP is of great potential to Australia's economic and social development (Commonwealth Scientific and Industrial Research Organisation [CSIRO], 2008). EU came up the concept of "blue growth" in 2012 (Committee of the regions, 2013). Therefore, many countries use

${ }^{1}$ Surface water and underground water are internationally defined as blue water. Rainwater that has not yet entered runoff is called green water, while gray water refers to discharged up-to-standard waste water.

${ }^{2}$ Blue economy business model is presented by Gunter Pauli. In The Blue Economy: A Report to the Club of Rome 2009, he defined blue economy as a sustainable business model by living in harmony with nature.

${ }^{3}$ Blue economy is a lifestyle that coexists with ocean, utilizes maritime resources and maintains a sustainable relation with ocean.
"Blue Economy" as a policy tool or means to drive economic growth and create jobs. Focused on revitalizing economy, the marine industrial activities include construction, transportation, mineral resources development, ship building, communication cable laying, pharmaceutical enterprises, equipment deployment, sustainable energy from waves, currents, seaside leisure tourism, and fisheries and aquaculture. In addition to traditional marine development activities, marine oriented information and science sectors are playing an increasingly stronger role in boosting blue economy development.

Blue economy needs compliance with Sustainable Development Goal 14, with the attribute focused on conserve and sustainably use the oceans, seas and marine resources. The core is to realize social economic development and dynamic balance of resources and environment. In their second preparatory meeting summary, The United Nations Commission on Sustainable Development acting as Preparatory Committee highlighted approaches to adopt "blue economy," and believes it is consistent with the core contents of RIO+20 Summit (IOC/UNESCO et al., 2011). Green economy mentioned in Rio+20 negotiations represents a transformation of economic development model. International society tends to refer blue economy to green economy or green development model in ocean and coastal zone development and management (Rio +20 Pacific Preparatory Meeting, 2011). Based on analysis on marine industrial activities and the health of marine eco-system, we should maintain a healthy marine and land ecosystem, solve pollution such as marine transport waste and plastic litter and microplastic, mitigate the global change effects, and construct a blue economy sustainable management model based on maintaining a healthy ecosystem.

\section{As "Blue" Signifies the Sea, Many Countries Consider the Blue Economy Refers to Marine Economy}

United States Secretary of Commerce, addressed in 2012 Capitol Hill Ocean Week that United State's sea area actually has always been a strong economic engine. Some people refer it as "blue economy". For example, Australia believes that the blue economy includes traditional and emerging marine industries and regards the value of marine industry as the value of the blue economy. India regards the blue economy as economic activities relying on the marine ecosystem or seabed. Blue development should increase the protection of adjacent waters, which means to enlarge blue economy space by expanding our development and protection to all marine (coastal and open ocean-deep sea) ecosystems. While alleviating pressures that reach the ocean originate in land and it is through atmospheric, riverine or connectivity that impacts reach the coastal ocean, we can further enhance our cognition toward the ocean.

\section{Blue Economic Definition Overview Blue Economy Is a Strategic Framework}

Australia believes the essence of blue economy is to promote the development of marine industry which ecologically,

${ }^{4}$ Blue growth is defined as "smart, sustainable and exclusive economic and employment increase generated from ocean, ocean and coastal zone." 
economically and socially benefit from marine ecosystem and ensure that the ecosystem-based management model should be the core in decision-making process of industrial and community development (Australian Government, 2012).

\section{Blue Economy Is a Kind of Policy}

In 2009, Maria Cantwell, United States Senator of Washington State, pointed out in the opening statement of the hearing on "The Blue Economy: The Role of the Oceans in our Nation's Economic Future" that "The "Blue Economy" - the jobs and economic opportunities that emerge from our oceans, Great Lakes, and coastal resources - is one of the main tools to rebuilding the United States economy."

\section{Blue Economy Is a Part of Green Economy}

UNEP and other international organizations extract blue economy from green economy. They encourages to tackle climate change via low-carbon and resource-efficient shipping, fishing, marine tourism, and marine renewable energy industries (UNEP et al., 2012).

\section{Blue Economy Is a Sustainable Marine Economy}

"We assume, "blue economy" is a sustainable marine economic development model. It is a new development mindset and its essence is to develop marine economy while protecting marine ecosystem well and finally achieving sustainable utilization of resources." Wang Hong said, Director of State Oceanic Administration under the Ministry of Natural Resources of the People's Republic of China, in China Marine Workshop of the United Nations Conference on Sustainable Development in 2012.

\section{Blue Economy Is Marine-Based New Technology Economy}

In its research report, Commonwealth Scientific and Industrial Research Organisation (CSIRO) of Australia mentioned "blue GDP," stressing that while developing diversified ocean-based industries, the idea of social and environmental sustainability has been implemented in the development under the support from new marine technologies and emerging industries (Commonwealth Scientific and Industrial Research Organisation [CSIRO], 2008).

\section{Summary}

In summary, Blue economy, as a macro economy concept, involves every aspect of national and global governance, economic development, environmental protection and sustainability and international communication. Blue economy is an integration of sustainable development and green growth. It highlights an overall-planning and coordinated development between marine ecosystem and ocean and coastal zone economic system. Considering the above features, we define the blue economy as sustainable productive, service and all other related activities using and protecting coastal and marine resources. There are many challenges in doing this which involve all sectors in the economy from private/industrial to research and development to NGOs to government policy. The complexity mentioned above offers both opportunities and barriers. The following sections address this from the perspective of selective use cases and experience moving forward. These perspectives are integrated near the end of the paper with approaches toward the balance of growth and ecosystem sustainability.

\section{BLUE ECONOMY THEORETICAL CASES}

This paper analysis the blue economy theories cases focus on three aspects: national macroeconomic management, policy framework and management technology.

\section{National Macro-Economic Strategies}

Since 2012, blue economy has entered the phase of practice and exploration. Some countries and regions have proposed strategic frameworks and action plans for developing the blue economy.

\section{EU's Blue Growth Strategy and Blue Innovation Plan}

In 2012, the European Union proposed the "Blue Growth" strategy, specifying that Blue Growth will be the core of marine policies and stating clearly key development areas and specific measures for the future. Blue Growth Strategy has launched initiatives in many policy areas related to Europe's oceans, seas and coasts, facilitating the cooperation between maritime business and public authorities across borders and sectors, and stakeholders to ensure the sustainability of the marine environment. In 2014, the Blue Economy Innovation Plan was launched, specifying that the plan will be executed from three aspects: (I) Develop sectors that have a high potential for sustainable jobs and growth, (II) Essential components to provide knowledge, legal certainty and security in the blue economy and (III) Sea basin strategies to ensure tailor-made measures and to foster cooperation between countries. In 2017, the EU issued the Report on the Blue Growth Strategy Toward More Sustainable Growth and Jobs in the Blue Economy, this report examines what has been learnt and what has been achieved since 2012, what is ongoing and what is still missing. Five aspects are described in the report: (I) pushing for growth in five focus areas, including blue energy, aquaculture, coastal and maritime tourism, blue biotechnology, sea bed mineral resources, (II) The benefits of marine data, spatial planning and maritime surveillance to facilitate growth in the blue economy, (III) promoting a partnership approach, (IV) boosting investment and (V) making blue growth strategy fit future challenge.

\section{Indonesia's Sustainable and Equal Growth of Marine and Coastal Regions}

Indonesia proposed the principles of developing marine and fishing industries based on their blue economy concept to: formulate comprehensive economy and environment protection policies; boost regional economic development; realize sustainable development by promoting clean production systems and encourage creative and innovative investment. The highlights of developing blue economy in Indonesia include: develop marine fishery, marine transportation, tourism, energy and material production industries based on the blue economy concept; further improve and coordinate marine 
and land economy national policies; develop blue economy demonstration zone; strengthen connections between trade and infrastructure and promote the development of technology and human resources. In addition, Indonesia also plans to set up blue economy demonstration zones in Lombok and Anamabs islands and Tomini bay, for exploring the blue economy model featured with marine industry, fishery, breeding, seaside tourism industries, small island collective, regional and bay development.

\section{Blue Economy Development Policy Guidelines}

\section{Scientific Innovation of the Marine Industry}

China has been pushing forward scientific innovations of the marine industry and has established six national marine economic innovation and development demonstration areas and sevennational industrial demonstration bases for rejuvenating marine industry with science and technology, of which several projects have achieved applaudable results, including Shandong Peninsula Blue Economic Zone, Blue Silicon Valley and the strategic cooperation among marine parks and bases in the Yangtze River Delta region.

\section{Shandong peninsula blue economic zone}

In 2011, The Shandong Peninsula Blue Economic Zone Development Plan was officially approved by the Chinese State of Council. It is China's first regional development strategy to focus on the marine economy (National Development and Reform Commission, 2011). The strategic positioning of Shandong Peninsula Blue Economic Zone is to develop into a modern marine industrial cluster with relatively strong international competitiveness, a world-leading education center of marine science, a pilot zone for national marine economic reform and opening up and a national key demonstration zone of marine ecological civilization. By 2015, Shandong Peninsula Blue Economic Zone has established a basic system of modern marine industry, significantly strengthened comprehensive economic strength, significantly improved the independent innovation capability of marine science and technology, prominently improved the quality of ocean and land ecological environment, constantly improved the landscape of the opening up of marine economy, and led other areas to achieve the general requirements of building a moderately prosperous society in all aspects. By 2020, Shandong Peninsula Blue Economic Zone will develop into a blue economic zone that features developed marine economy, optimized industrial structure, harmonious co-existence between human and nature and take the lead to fundamentally achieve modernization.

\section{Blue silicon valley}

On January 31, 2012, the work and management committees of Qingdao Blue Silicon Valley core area were officially established, marking the commencement of the overall planning and construction of Qingdao Blue Silicon Valley (Qingdao Municipal Government, 2012). Aiming to establish "China Qingdao Blue Silicon Valley, a new town of marine science and technology" and highlighting the functions of incubating scientific achievements and driving forward innovation, the project plans to build five new towns that deeply integrate scientific research, education and living. It also centrally plans key platform projects of marine science and research, education, achievement conversion and academic exchanges, speeds up the clustering of marine high-tech research and development, high-tech talents, high-tech industry and service organizations, significantly improves the abilities of independent innovation, achievement conversion and industry cultivation, endeavors to establish world-leading centers for marine scientific and technological research and development, centers for incubating and trading marine achievements, centers for cultivating emerging marine industries, centers for clustering blue education and talents, centers for blue tourism and healthcare, and becomes an innovation platform that enables China to scientifically develop and utilize marine resources and links global marine scientific research resources.

\section{Strategic cooperation among marine parks and bases in the Yangtze river delta region}

On June 8, 2018, several marine industrial parks and bases in the Yangtze River Delta region signed agreements to implement regional strategic cooperation. The strategic cooperation of marine industries in the Yangtze River Delta include five parks and bases in Nantong, Zhoushan, Shanghai Pudong, and Ningbo. The establishment of these parks and bases has two major foci: firstly, to elevate industrial cooperation, comprehensively manage industrial projects and resources to facilitate necessity-based selections, build service functions to guide project practices, promote orderly transfer and cluster development of marine industry within the region; secondly, to deepen cooperation between scientific innovation and talents, encourage colleges and institutions, scientific institutes and enterprises to establish cooperative research and development institutions and joint centers for technology transfer, achieve communications and integration in introducing marine talents, build joint mechanism for educating and cultivating talents and establish common criteria in recognizing talents (Chinese State of Council, 2014).

\section{Widen Space for Blue Economy \\ Widening China's blue economy space}

The 13th Five-Year Plan for Economic and Social Development of the People's Republic of China requires to widen space for the blue economy. In supporting industrial development, the Plan suggests to complement domestic fishery with distant water fishery to protect and maintain coastal fishery resources, restore marine ecological environment and effectively improve the ongoing healthy development of distant water fishery. The Plan proposed several key maritime projects:

(1) Dragon in the deep-seas Achieve breakthroughs in key technological development of the Dragon PalaceI deep-sea experimental platform and construct deepsea mobile and bottom-supported experimental platforms. Research and develop a system for integrated deepsea environmental monitoring and activity exploration. Develop a shared platform for deep-sea equipment applications (China's search, 2018). 
(2) Snow Dragon's Polar Exploration Establish a new shore-based observation station at Arctic Pole through cooperation, establish a new research station at Antarctic Pole, build new advanced icebreakers, improve Antarctic aviation capabilities, and complete the basic framework for land-sea-air observation platform in the polar regions (Science 24 hours, 2016). Research and develop exploration technology and equipment suitable to the polar environments, establish a service platform for the provision and application of information regarding the polar environments and potential polar resources.

(3) The multi-dimensional global ocean observation network Make overall planning for the layout of the national ocean observation (monitoring) network, move ahead with the development of real-time online monitoring systems and overseas observation (monitoring) stations for the marine environment, work toward establishing a multidimensional global ocean observation (monitoring) system, and strengthen observation and research of marine ecosystems, ocean currents, and maritime meteorology.

\section{Blue economy in deep ocean stewardship initiative}

A potential and topical sector for the promotion of the Blue Economy in our deep oceans is that of deep seabed mining for marine minerals and trace metals (Cuyvers et al., 2018; Lusty and Murton, 2018). The demand for minerals is increasing owing to reserves in land-based mines dwindling, as well as the potentially extensive environmental and social consequences of mining on land. Some suggest that land-based mining and recycling existing minerals alone may not fulfill the future demand for these resources (Hein et al., 2013). Minerals have potential for diverse industrial applications, including for green technologies, hence there is increasing attention to their extraction from the deep sea. Consequently, significant investments have already been made by some countries in terms of exploration for deep seabed mineral resources, developing sophisticated technology and conducting feasibility studies (for example the Japanese conducted their first test mining in 2017), and developing economic models under different commodity price scenarios and other geologic and financial considerations (Van Nijen et al., 2018; Volkmann et al., 2018). The exploitation of materials such as polymetallic sulfides, polymetallic nodules, cobalt-rich ferromanganese crusts (for nickel, copper, cobalt, zinc, manganese, gold, silver and other metals), as well as rare-earth elements, are of economic interest especially as these marine sources are often high-grade ores and therefore very valuable. Some of the main focus areas for this industry are the polymetallic nodules on the abyssal plain in the clarion-clipperton zone (CCZ) in the central Pacific Ocean, the seafloor massive sulfide deposits associated with hydrothermal vents in the Indian Ocean, and ferromanganese cobalt-rich crusts associated with seamounts in the West Pacific Ocean (Levin et al., 2016; Cuyvers et al., 2018).

Mining activities within national jurisdictions are governed locally but the extensive resources of those outside EEZs in The Area are under the jurisdiction of the International Seabed Authority (an intergovernmental body established by UNCLOS in 1982 to organize and regulate all mineral-related activities.
Although deep-seabed mining may generate income for some nations, it will come at a high environmental cost with many unknown risks, some of which may become apparent only in the distant future (Levin et al., 2016; Gollner et al., 2017; Jones et al., 2018).

Deep-seabed mining comes with significant regulatory challenges (Bräger et al., 2018; Lodge and Verlaan, 2018). The environmental and social costs and future risks must be as fully understood as possible and be weighed against the short-term monetary gain (Voyer and van Leeuwen, 2019). In addition to obvious destruction of sea life living at the mine site, there are other adverse effects on biodiversity and ecological processes such as those associated with sediment-plume generation, toxic chemical release, noise, etc. (Levin et al., 2016; Vanreusel et al., 2016; Gollner et al., 2017; Jones et al., 2017; Tilot et al., 2018). The cumulative effects of these, along with other ocean pressures such as climate change (Guidetti and Danovaro, 2017) and pollution, need to be considered during this pre-mining phase in order to properly assess impacts. Integrated management of multiple economic sectors is a central tenet of blue growth and socially optimal use of ocean-based natural resources, but the mechanisms of implementation remain poorly understood (Klinger et al., 2018). Open access to environmental data is essential (Voyer et al., 2018) in order to achieve industry transparency and sound environmental management.

Deep-sea mining is, at the time of writing, rapidly approaching the commercial mining phase in multiple oceans, both in areas within and beyond national jurisdiction. There is an urgent need to identify and develop comprehensive, ecosystembased management practices for deep-ocean environments subject to mineral extraction (Durden et al., 2017; Tunnicliffe et al., 2018). While overarching environmental objectives are needed, some practices will be resource and locality-specific. Transparent criteria for deep-sea institutional and corporate social responsibility also need to be established to respond to the challenges associated with sustainable use of resources (Ardron et al., 2018). Proactive development of environmentally considerate extractive technologies, practices, frameworks and policies prior to the onset of commercial mining (and taking into account the precautionary principle) will help to ensure effective stewardship and preservation of the marine environment, whilst enabling the use of seabed mineral resources (Durden et al., 2017).

While deep-seabed mining is discussed as a case study here, the deep ocean features in numerous other elements of the Blue Economy (Ramirez-Llodra et al., 2011; Mengerink et al., 2014). Deep-water fishing, which takes the form of bottom trawling, long lining, and now new mesopelagic fisheries are increasingly subject to ecosystem-based management (e.g., Grehan et al., 2017). The designation of protections (e.g., vulnerable marine ecosystems, marine protected areas, areas of particular environmental interest), the preparation of environmental impact assessments, stock assessment, fisheries regulations and other facets will all benefit from increased scientific input and stewardship approaches (Mengerink et al., 2014). Exploitation of gas hydrates or hydrothermal gradients as energy sources, of marine genetic resources for biopharmaceutical or industrial 
uses, and use of space for telecommunications cables are additional opportunities that would benefit as well. There is also a growing need for consciousness and regulation about carbon emissions and other climate impacts, debris, pollutants and contaminants introduced to the deep ocean associated with blue industries (Ramirez-Llodra et al., 2011).

\section{Blue Economy Management Technology Data Analysis and Information Delivery Support Observing Enterprises}

The great lakes observing system (GLOS) is 1 of 11 Regional Associations in the integrated ocean observing system (IOOS). As certified regional information coordination entities, IOOS regions play a crucial role in coordinating their science and technology communities around the data and information priorities of resource managers and policy makers. In a geography as large as the Great Lakes, there are many academic, government and private entities that work in monitoring and science, and GLOS serves a role that is more focused on data management and aggregation services. Limited resources have also influenced the scope of GLOS' role in the region. Like other IOOS regions, GLOS provides direct resources to the sustained operations of local observing systems but in a more limited capacity. Similarly, GLOS has provided grants to partners for the development of models and information products or developed data tools and products directly, but typically as discrete projects that require further investment for sustained operations and maintenance.

The experience in the governance and management of GLOS provides a case study for why diversifying revenue is inherently important to sustaining observing and data management systems. Moreover, it has become critical for GLOS in a competitive market; one where organizations with similar names and broad missions can make it difficult to identify the best group for the job. GLOS is positioning itself to stay true to its mission while including non-traditional partners to achieve better results. The small size and 501c3 status of GLOS allows a less traditional approach to seeking partners and funding. GLOS addresses challenges in achieving its mission by applying creative funding and business models to areas of operations. Examples include (1) crowdsource funding to support the costs of ongoing operations and maintenance of observing assets; (2) multisector stakeholder agreements; and (3) service-based business models. While each of these examples has mixed success, they provide important insight about how the larger ocean observing enterprise might broaden its impact and grow the Blue Economy.

\section{Crowdsource and private fundraising}

As a function of its mission, GLOS provides financial support to an extensive network of over 35 nearshore buoys, gliders, and AUVs operating primarily in the nearshore areas of the Great Lakes, from Lake Superior to Lake Ontario.

An opportunity was presented when NOAA's Coastal Storms Program dedicated focus to the Great Lakes region and was looking to make smart investments in addressing critical information gaps related to coastal storms issues. Over the three-year period of working with the Coastal Storms Program ${ }^{5}$, GLOS worked with the National Weather Service to support the capitalization of four new, privately operated, nearshore buoys placed in areas of critical importance for beach safety and shipping stakeholders. The agreements with the buoy operators was clear that funding would support the capitalization of the buoys but a financial plan (outside of federal grant funding) for sustained operations and maintenance of the buoys needed to be in place and supported by the operators.

Each of the four operators had unique stakeholder relationships that influenced their approach to finding sustainable operating funds. Two operators, the Regional Science Consortium (Erie, PA, United States) and Purdue University (Wilmette, IL, United States and Michigan City, IN, United States) have primarily absorbed ongoing operation costs by incorporating them into the regular outreach costs of affiliated education centers, the Tom Ridge Environmental Center and Illinois-Indiana Sea Grant, respectively. The other two operations, Northern Michigan University (Munising, MI, United States) and LimnoTech (Port Sheldon, MI, United States) relied more directly on donations from individual stakeholders.

In 2016, GLOS partnered with local buoy operator LimnoTech to demonstrate the viability of using private fundraising as a funding model to offset the annual buoy operations costs. The popular Port Sheldon buoy in Lake Michigan ${ }^{6}$ that averaged 8,500 pageviews per week during the summer of 2018, is supported 100 percent by local contributions ranging from individuals to local fishing clubs, marinas, local government contributions, television news stations, and even a car dealership.

Though this appeared to be a successful model for local stakeholder engagement, emerging challenges cause concern that this type of fundraising is not a sustainable model for ongoing operations support. These experiences suggest that, while this might be a useful strategy for supplemental funding, it is not enough to serve as a sole funding source.

\section{Multi-sector stakeholder agreements}

As expensive buoys outlive their initial funding programs, GLOS is engaging public utilities to take on the ongoing expenses, leaving them with a high-quality observation instrument and GLOS with continued shared data and equipment utilization. The most successful demonstration of this is the service agreement between GLOS and the City of Cleveland, Ohio which involves a multi-sector partnership to support the operations of three buoys that provide critical water quality information for the city's drinking water system that serves over 1.5 million residents in the Cleveland area.

During the summer of 2006, over a twelve-day period, the City of Cleveland's water department was inundated with complaints from their customers about the taste, odor and color of the water. Areas of low oxygen and decomposing organic

\footnotetext{
${ }^{5}$ The Coastal Storms Program is a nationwide effort led by NOAA to increase mitigation efforts and reduce the risk associated with coastal storms. The program brings together a variety of federal, state and local organizations with the purpose of reducing loss of life and negative impacts on coastal property and the environment caused by coastal storms.

${ }^{6}$ http://glbuoys.glos.us/45029
} 
matter, also known as hypoxia zones, were moving toward the city's water intakes. As Cleveland's information needs grew, NOAA's Great Lakes Environmental Research Lab and GLOS worked together to consider options for transitioning existing hypoxia research efforts at GLERL toward developing a more operational monitoring capacity for the city. Building from the process utilized with the Coastal Storms Program, GLOS used competitive grant funding to support the capitalization of an additional monitoring buoy to expand monitoring coverage in Lake Erie. Then in 2016, Cleveland Water entered into a service agreement with GLOS where Cleveland Water provides funds annually to GLOS to manage the annual buoy deployments, data collection and delivery.

The operations of the buoy are carried out by LimnoTech, a private engineering firm, with a portfolio of supporting science and engineering projects across the region, and in Lake Erie in particular. LimnoTech leverages the buoy operations work to support other clients including LEEDCo., a wind-energy development company that has also contracted with LimnoTech for the operations of another buoy in the area to assist with wind farm siting and planning. This multi-sector partnership serves as a model for GLOS in structuring other types of service-based agreements to support its data management and aggregation operations. Acknowledging the limitation of United States federal funding to support observations at regional and local level, it is important to consider the appropriate role and creative options for federal and local government, the private sector, and others to work together to meet important monitoring needs.

\section{Data service based business models}

As the management of GLOS has matured and evolved over time, it has become clear that data aggregation, integration, and service delivery are core to the organization's value proposition and are, arguably, a more appropriate function of its mission to prioritize resources toward given existing funding limitations at the Federal level. GLOS has several examples of partner agreements with both federal agencies and non-federal partners where data services, rather than direct support for observations, are the primary focus of the scope of work.

A recent example is the current Cooperative Agreement between GLOS and the United States Geographic Survey (USGS) to support improved coordination around various bathymetric and lake-bottom habitat mapping efforts in the region. Vast areas of the Great Lakes have not been mapped for bathymetry since the 1950s, leaving a major data gap that impedes progress in natural resource and habitat management. Contemporary mapping efforts are taking place with superior technology in a few constrained geographies, but largely in a piecemeal and uncoordinated fashion that limits benefits to multiple users. Multiple federal and state agencies, and academic institutions are engaged in bottom mapping activities as well as benthic biology in both the United States and Canada. These groups have begun to coordinate through the bottom mapping workgroup (BMW); an ad hoc group form with the goal of harmonizing collection, processing, and sharing of continuous high-resolution maps of Great Lakes bathymetry, sonar reflectance, bottom type classifications, and derived data products. While the
BMW provides an effective regional coordinating mechanism, its progress has been hindered by the absence of dedicated capacity to coordinate meetings and outreach, create and manage web content, and carry out other activities. Although regional coordination on the issue of lake bottom mapping is increasing, essential pre-requisites to strategic investment in new data acquisition are missing.

Through the Cooperative Agreement with GLOS, USGS is committing resources to support a full-time employee to support coordination of data providers around the theme of bottom mapping, conduct a regional data inventory and needs assessment, draft lake floor mapping standards for the Great Lakes, and build the data infrastructure needed to discover, archive, and serve data to the public.

The USGS views GLOS as uniquely qualified to undertake this role. As the regional association for the Great Lakes within the United States integrated ocean observing system (IOOS) that is overseen by an inter-agency governing council, GLOS has a neutral posture that will allow them to work productively with a variety of agencies in the United States and Canada as well as non-federal partners including academic institutions and state agencies. GLOS is also able to leverage its existing infrastructure to support data assembly, quality control, discovery and access services for multiple data types and has a well-visited web service for data visualization and download.

This agreement serves as an example of how the role GLOS serves to the Great Lakes region is evolving with a greater emphasis toward that of a data assembly center (DAC) or regional information coordination entity (RICE). This is a good thing, as it is precisely the purpose and presumed benefit of the Certification process required through the Integrated Coastal and Ocean Observation System Act of 2009 (2009 ICOOS Act). ${ }^{7}$ However, as this becomes a more viable area for growth, it undoubtedly has implications for the overall management and business model of the organization. These types of data services are growing in demand, and as GLOS builds its reputation and competencies as a certified regional information coordination entity, it can respond more often to requests for these services. GLOS is evolving its business model in this area where basic operations can be implemented as part of its mission, but cost recovery is required to grow and expand services.

\section{Delimitation Technology for China's Marine Spatial Planning}

Faced with the grim situation of tight resource constraints, serious environmental pollution, and degraded ecosystems, the Chinese government is taking the road of sustainable development. The concept of ecological civilization that respects nature, conforms to nature, and protects nature is established. In March 2018, China launched the largest reform of the State Council in the past 40 years, in which resources and environmental reforms were prominent. The Ministry of Natural

\footnotetext{
${ }^{7}$ In March of 2009, President Obama signed the Integrated Coastal and Ocean Observation System Act of 2009 (ICOOS Act). establishing statutory authority for the development of the United States integrated ocean observing system (IOOS). The ICOOS Act mandates the establishment of a national integrated system of ocean, coastal, and Great Lakes observing systems coordinated at the federal level.
} 
Resources has been assembled, and performed the responsibilities of owning all natural resource asset, managing all territory utilization, protecting and rehabilitating ecological environment uniformly. The "two unification" responsibilities start a new era in natural resource management in China.

China is in a critical period transferring from highspeed development to high-quality development. The resource and environmental carrying capacity and the territory space development suitability are important scientific propositions which represent the interaction and coordinated development between man and nature. Since 2010, it has gradually become a basic work for central and local governments to determine regional strategies and policies, and make development planning. The resource and environmental carrying capacity refers to the comprehensive support levels of natural resource endowment conditions to human activities in a certain space, and is characterized by four aspects: resources, environment, ecology and disasters. We can evaluate the relative level of carrying capacity and identify the problems and risks of current utilization, thus promoting harmonious development of man and nature. The territory space development suitability is oriented to different development and utilization, considering spatial integrity and connectivity, location advantage, traffic convenience and other indicators, to judge the appropriateness of different development and utilization modes. It can provide scientific planning for development and utilization, and promote high quality development. At present, China has taken the assessment of resource and environmental carrying capacity and the territory space development suitability as the basis and premise of territory space planning. The dual evaluation and territory space planning at all levels will be launched soon, guiding scientific planning with resources and environment constrains, and leading green and high quality development with scientific planning (National Development and Reform Commission, 2017; China Research Intelligence Group, 2018).

\section{Comprehensive Governance of Marine Environment}

The Chinese Government attaches great importance to the prevention and control of marine environmental pollution. On November 30, 2018, the Ministry of Ecology and Environment, the National Development and Reform Commission and the Ministry of Natural Resources jointly issued the Action Plan for the Struggle of Comprehensive Governance of the Bohai Sea (Ministry of Ecology and Environment et al., 2018). The Action Plan clearly defined the overall requirements, scope and objectives, key tasks and safeguards for the comprehensive governance of the Bohai Sea, and put forward the timetable and roadmap for the Struggle of Comprehensive Governance of the Bohai Sea. The Action Plan proposes to improve the ecological environment quality of the Bohai Sea through comprehensive three-year management and solve the outstanding ecological and environmental problems in the Bohai Sea. By 2020, the proportion of the coastal waters in the Bohai Sea with good water quality (first and second water quality) will reach about $73 \%$, the natural coastline retention rate will remain around 35\%, the coastal wetland rehabilitation scale will not be less than 6900 hectares, and the coastline rehabilitation will increase by about $70 \mathrm{~km}$.

The Action Plan calls for four key actions: land-based pollution control action, marine pollution control action, ecological protection and restoration action, and environmental risk prevention action. The land-based pollution control actions include: pollution control of rivers entering the sea; strict control of industrial pollution source discharge, completion of illegal and unreasonable clean-up of sewage outlets; promotion of agricultural, rural and urban pollution prevention and control; and reduction of land-based pollutants into the sea. The marine pollution control actions include: implementing marine aquaculture pollution control; implementing ship and port pollution control; carrying out comprehensive improvement of fishing port environment; marine garbage pollution prevention; and establishing a division of responsibilities and coordination mechanism for land and sea planning. The ecological protection and restoration actions include: ecological protection of coastal zones, delineation and strict observance of the red line of marine ecological protection in the Bohai Sea, comprehensive regulation and restoration of estuaries and bays, comprehensive management and restoration of coastal and shoreline, and conservation of marine living resources. Environmental risk prevention actions include: implementation of landbased emergency environmental incident risk prevention; implementation of marine oil spill risk prevention; marine ecological disaster warning and emergency response.

\section{BLUE ECONOMY APPLICATION CASES}

The blue economy application cases in this part mainly include two parts: One part is the science-based products and services that can underpin the development of the Blue Economy, seven AtlantOS use case examples were developed (Figure 1). The other part is China's marine integrated management based on ecological environment. This paper classifies all the cases into disaster prevention, pollution prevention, Marine industry support, system platform and ecological restoration.

\section{Disaster Prevention Assessing Harmful Algal Bloom Evolution in EU Atlantic Shelf Seas}

Aquaculture is identified as a Blue Growth priority to ensure the sustainable supply of seafood to help meet increased food demands of the growing global population. Harmful Algal Blooms (HABs) are a recognized global problem with annual losses to aquaculture running into billions of Euros (Bernard et al., 2014). The AtlantOS HAB use case focuses on creating a weekly HAB bulletin for three European study areas in Norway, Ireland, and Spain. Experts who prepare the bulletins use the in situ ocean observing system, satellite data, and available numerical marine hydrodynamic modeling to provide a sciencebased product to indicate the current $\mathrm{HAB}$ status in areas of interest, accompanied by text describing the likely HAB occurrences in the days ahead (Cusack et al., 2018; example bulletins). Efforts in other parts of the world, the importance 


\section{Atlant@S Societal Benefit Pilot Actions}

"from observing/information system data to informed decisions"

\section{กิำ Users: Policy Makers, Industry, Public, Scientists}
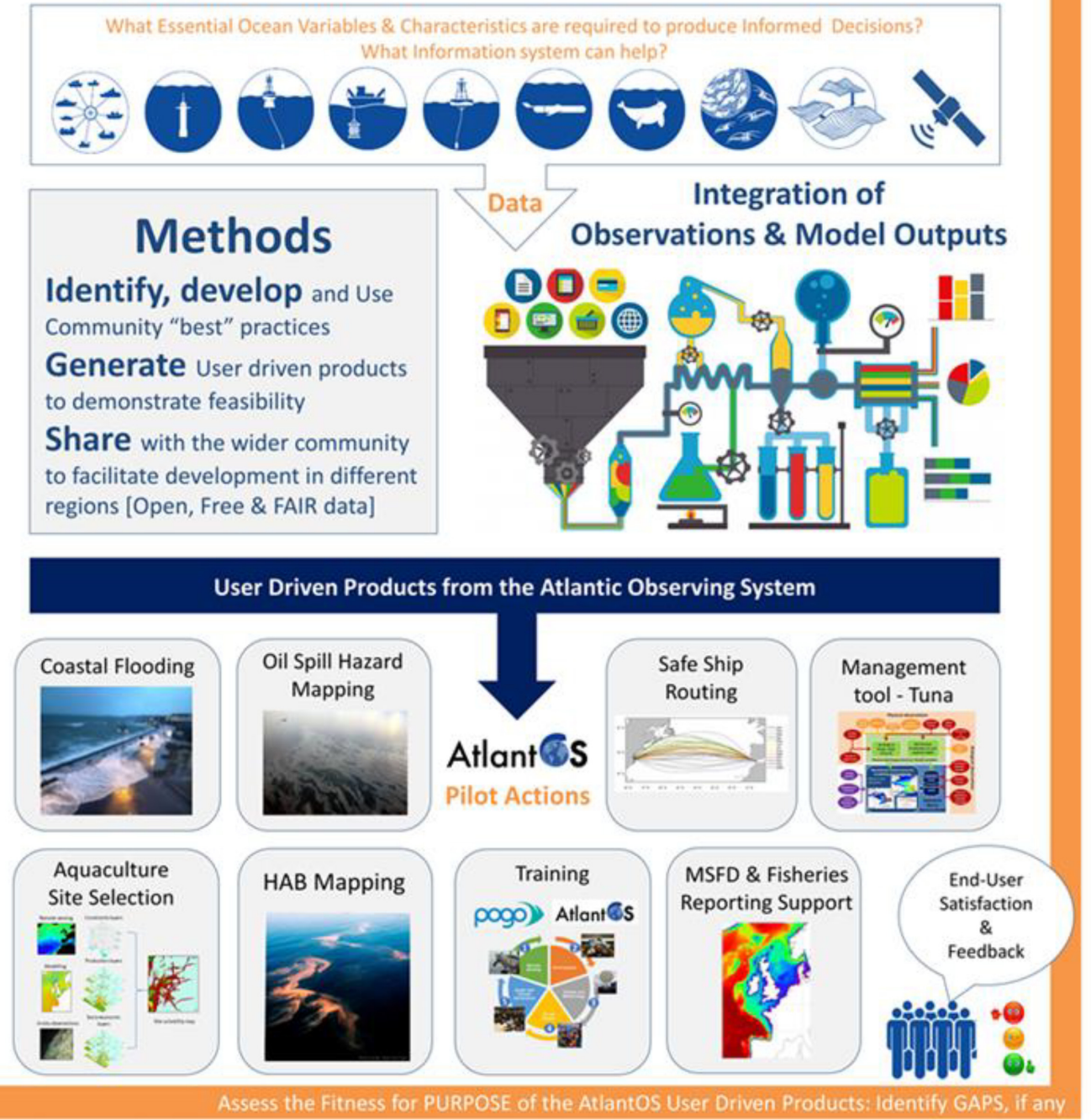

FIGURE 1 | AtlantOS societal databenefit pilot actions poster.

of co-development, and future expectations are discussed in Anderson et al. (see HABs white paper within this SI). In Europe, a key driver for HAB bulletins is to support industry on-site management decisions, such as optimizing farm practices and planning business activities to mitigate/reduce shellfish and finfish mortalities due to HABs.

\section{Assessing and Mapping Ocean Hazards Related to Coastal Flooding and Storm Surges}

Coastal flooding is one of the major challenges of global climate change for humanity. It is estimated that by 2070, approximately
150 million people and $\$ 35,000$ billion of assets will be exposed to a 1 in 100 year flood event. Storm surges and oceanic waves are the major cause of extreme sea levels and devastating coastal impacts along many coastlines around the world with a significant human and economic cost. In order to improve our ability to assess the potential change of storm surge, it is critical to have a well-established baseline of the storm surge climate, based on consistent techniques. AtlantOS is laying the framework for a complementary international effort; developing a global storm surge climate has been adopted as a project under the IOC/WMO JCOMM Expert Team for Waves and Coastal Hazards. Statistical 
methods to both tide gauge data and multi-decadal runs of hydrodynamical numerical models are a "main" activity for the Sendai Framework of Disaster Risk Reduction. In this use case improvements were made to estimate extreme sea levels around the Atlantic and more widely with a new understanding gained about how storm surges and high tides interact, providing proof that any storm surge can occur on any tide (Williams et al., 2016). The sciences based products developed in this use case will help to enhance the safety of coastal communities by supporting the decision making process related to planning coastal defenses and emergency response to severe coastal flooding.

\section{Pollution Governance}

\section{Mapping Ship Based Oil Spills to Estimate the Hazard That Maritime Transportation Represents to Atlantic Basin Coasts}

The AtlantOS "oil spill hazard mapping and disaster risk reduction best practices" use case developed a large ensemble oil spill simulation experiment to guide oil spill risk assessments and emergency management. Risk maps can now be rapidly produced, within five minutes, to help evaluate an oil spill hazard (Neves et al., 2018). The hazard/risk mapping and production of oil spill hazard bulletins in the Atlantic are generated in an open access oil spill hazard map portal called glamor. In emergency situations, the users can map the oil spill hazard spatial distribution for any Atlantic coastal area based on the average oil spill concentration found at the coastline. The product provides a decision support tool to coastal managers and governments to help guide emergency clean-up operations and decisions on the allocation of resources to targeted high risk areas.

\section{Overall Planning of Land and Sea to Strictly Control Pollutants}

China appointing local government heads as river chiefs and bay chiefs across the nation to clean up and protect its water resources. Shandong proposed new pollution prevention idea of "governing river first, treating land and sea in a coordinated way.” In Shandong, 15 rivers flowed into Laizhou Bay. In order to implement the responsibility of management and protection, Laizhou established a three-level "river chief" organization system of city, town and village. A total of 13 city-level "river chief," 44 town-level "river chief," and 662 village-level "river chief” were established. Since 2017, Laizhou has concentrated on the comprehensive management of Baisha River, Nanyang River and Zhenzhu River basins. A total of 42 million yuan has been invested, and about 25,000 meters of silt has been cleared up, more than 30 sewage outlets have been closed, and 64 polluted aquaculture households have been banned. After the linkage of the "river chief" and the "bay chief," the problem of repeated pollution in the Bay has been fundamentally solved (People's Daily, 2018).

\section{Marine Micro Plastics: Impact and Governance}

Microplastics are important component of marine litter, and also one of major global marine pollution problems (Arthur et al., 2009; Raubenheimer and McIlgorm, 2018). Microplastics are mainly caused by human activities (Cole et al., 2011). At present, microplastics have spread all over the world's major marine areas, and have had varying degrees of impacts on human development and the ecological environment, and some of the impacts are even devastating (Jambeck et al., 2015). Studies have found that microplastics have been found in biological cells, blood circulation systems and even the brains (Yu et al., 2018). In addition, a large number of plastics accumulate in estuaries and coasts, which will affect the marine ecological environment in coastal areas, and then affect the tourism industry, residents' lives and port terminals. Therefore, marine microplastics will adversely affect the sustainable utilization of blue economy.

The government is the coordinator of cooperative governance of microplastics. As the dominant government in the whole governance system, its functions include leadership, organization, coordination and supervision. Take China as an example, since 2007, China has actively carried out marine debris control work, and organized marine debris monitoring and evaluation in more than 50 representative areas along the coast. The monitoring area mainly includes areas with high public concern as well as sea areas where there is a large amount of potential marine debris and may affect the environmental quality of the sea area. The monitoring contents include types, quantities, weights and sources of beach garbage, floating garbage and submarine garbage. Since 2016, China has also implemented microplastic pilot monitoring, microplastics research and prevention research, polar and ocean micro-plastics investigation and monitoring. China also scientifically and strictly manages marine debris in accordance with relevant laws and regulations, technical standards and international conventions, and prevents solid waste such as plastic waste from affecting the marine ecological environment.

Since 2014, the United Nations has paid great attention to the pollution and control of microplastics. It has formulated a series of rules and taken relevant actions to strengthen the control of microplastics. For example, in February 2017, the United Nations Environment Program launched a global campaign calling on governments, industries and consumers to reduce the production and overuse of plastics. The campaign aims to eliminate the main sources of marine waste by 2022: plastic beads in cosmetics and overuse of disposable plastic products. In addition, resolutions of the United Nations Environment Congress on marine waste and microplastics (UnEA1 Resolution I/6 on marine waste and microplastics, UnEA2 Resolution II/11 on marine waste and microplastics, UnEA3 Resolution III/20 on marine waste and microplastics) provide partial solutions to the control of microplastics. The program emphasized the importance of global cooperative governance.

Enterprises are the micro-economic organizations for the cooperative governance of microplastics, as well as the main source of marine microplastics. Worldwide, especially in some developed countries, the sustainable use of packaging and plastics is regarded as part of corporate social responsibility (Vince and Hardesty, 2017). In 2011, the Global Declaration on Marine Waste Solutions issued by the Global Plastics Industry Association showed that 60 industry associations in 34 countries have signed the Declaration. 


\section{Marine Industrial Support \\ Developing an Aquaculture Site Selection Support \\ Tool That Assesses Regional Oceanographic Conditions in Order to Identify Suitable Aquaculture Sites}

Aquaculture is the fastest growing food production system in the world and a key ocean based economic activity sector expected to expand under the EU Blue Growth initiative. Such drivers, at local and global level, incentivize aquaculture to move offshore to the unprotected waters of the open ocean. Furthermore, appropriate site selection is needed to avoid competing demands for access and use of space, and prevent potential negative environmental impacts of the operations. In this AtlantOS use case, a GIS layered approach to identify potential offshore aquaculture sites was used. Ocean in situ and modeled GIS products were created and supported by data layers derived from satellites and/or administrative layers, e.g., coastline, infrastructure, fishing Areas, areas of conservation etc. (Dale et al., 2017). This initial pilot study showed that there is great potential for the use of GIS support tools to integrate information from in situ observations and model outputs over a hindcast period and then to couple this information with existing site decision tools and administrative layers, so potential aquaculture license applicants can pinpoint sites for further exploration to help the aquaculture sector develop in an environmental, economic and socially sustainable way.

\section{Developing a Fisheries Management Tool for Atlantic Albacore Tuna}

Progress in fish population modeling integrating environmental variables derived from Earth Observation and Operational Oceanography (COPERNICUS CMEMS program) has made it possible to create a demonstration of a near real-time forecast of one key tuna stock in the Atlantic Ocean. The AtlantOS use case developed a demonstrator for the albacore tuna to simulate in near real-time the change in abundance over time and space of this species by life stages i.e., larvae, juveniles, adults (Lehodey et al., 2017). The operational product is available on the seapodym model web site and is a great step toward improved real time monitoring of fishing activity and stock assessment that feed into the conservation measures, such as Total Allowable Catch, established by the International Commission for the Conservation of Atlantic Tunas.

\section{Mapping CO2-Optimal Maritime Tracks, Based on Ocean State and Ocean Circulation}

Regulatory decisions on ballast water treatment (2004), low Sulfur fuels (2008), and greenhouse gasses (2018) have been adopted by the International Maritime Organization (IMO) of the United Nations. In particular, the initial strategy for GHG reduction (MEPC.304(72), 2018) envisages a significant reduction of $\mathrm{CO} 2$ emissions from ships before mid century, along with an increase in energy efficiency of maritime voyages. The latter can be achieved through technological, design, or operational measures. The contribution of the AtlantOS use case on ship routing is to provide maps of optimal ship tracks, which maximize the operational energy efficiency of the voyage (EEOI).
Preliminary results for a North Atlantic passage indicate that the monthly average efficiency can be raised by up to about $10 \%$, with a non-negligible contribution from the exploitation of the major ocean currents such as the Gulf Stream (Mannarini et al., 2018). In order to achieve these results, VISIR, an open source model for ship routing (Mannarini et al., 2016) was employed and further developed. The new modeling capabilities (including the source code) will be published soon. AtlantOS also plans to showcase VISIR results for low-carbon routes in the Atlantic through a dedicated web interface, providing a contribution to community efforts toward more sustainable navigation.

\section{System Platform Services}

Marine reanalyses enhance information collected from the in situ ocean observing system by assimilating observations into the North-west European Shelf Seas (NWS) numerical models, keeping the models close to reality, and providing a complete estimate of the evolving state of the ocean. The reanalyses (with in situ and remotely sensed observations) underlie the recent Copernicus Ocean State Report, providing an assessment the ocean state in the previous year. Understanding gained from reanalyses directly (through analysis of the reanalysis) and indirectly (i.e., via the Ocean State Report), can inform policy decisions relating to sustainable management of the NWS.

The use of NWS reanalyses, with global seasonal forecasting systems (such as the Met Office GloSea5 system), may extend NWS (temperature and salinity) predictability into the monthlyto-seasonal timescale, which would be of great benefit to European environmental and fisheries management (Tinker et al., 2018). Tinker et al. (2018) identified (and assessed) a number of pathways toward developing such a forecast, however, many challenges remain, and much research is required. Seasonal forecasts for the NWS would assist future operational management the NE Atlantic shelf seas and also has the potential to support marine operations sensitive to wind/wave conditions and currents such as the oil and gas industry, shipping, commercial and recreational fisheries.

\section{Ecological Restoration}

In the past 5 years, China has intensified efforts of wetlands treatment and restoration. With Blue Bay treatment projects, the ecological project to restore wetlands by developing mangrove forests in the south and Chinese tamarisk forests in the north, and the ecological island-reef restoration project, China has supported coastal regions to restore and recover coastal wetlands of 4,100 hectares, restore shorelines of more than 260 kilometers and restore beaches of more than 1,240 hectares. It is the goal to, by the end of 2020, treat and restore coastal wetlands of no less than 8,500 hectares (State Oceanic Administration of China, 2015), and establish a new batch of national, provincial, municipal and county level wetlands.

From 2016, China has been implementing the Blue Bay project to treat and restore marine ecosystem, which focuses on bays and expands to cover coastal regions and other damaged regions. In 2016, Panjin, Qinhuangdao, Shanwei, Xiamen and other cities, 8 in total, became the first batch of Blue Bay cities approved by the Ministry of Finance and the State Oceanic Administration 
(Fang, 2016). Each city received central government subsidy of about RMB 300 million. Dalian, Qingdao and eight other cities were approved as the second batch Blue Bay cities in 2016. Each city received central government subsidy of about RMB 300 million. Moreover, according to implementation plans, the other part of supporting funds comes from local government financial funds and corporate/social funds, ranging from RMB 5 million to 4.5 billion. By the end of 2018, 18 Blue Bay projects are underway or near acceptance, with approximately $169 \mathrm{~km}$ of coastline, $2270 \mathrm{hm}^{2}$ of coastal wetlands, 11 islands and $38 \mathrm{~km}$ of beaches have been rehabilitated and restored. By 2020, Blue Action will focus on the governance of 18 bays suffering from serious pollution, push forward treatment and restoration of 50 small bays neighboring coastal cities, recover coastal wetlands of no less than 8,500 hectares, restore damaged near-shore seas of 4,000 square kilometers, treat and restore shorelines of $20 \mathrm{~km}$. Most Blue Bay projects include some monitoring capacity building activities to monitor remediation effects, including observatory construction, on-line monitoring, drone monitoring, for water quality, hydrology and sea area utilization real-time data.

\section{PROSPECT, PROPOSAL, AND DIRECTION}

To understand, utilize and protect oceans are the shared goals and responsibilities for all human being to achieve sustainable marine development in the future. At present, blue economy, as the new development concept and the "blue engine," is becoming an important driving force for achieving global sustainable development. Environmental observations play a powerful technical supporting role in realizing blue economy development. Today, we focus on the development of blue economy, in a wish to, through joint efforts, push forward the accord development between blue economy and global economy, society and ecosystem in the next decade.

We should shoulder global responsibilities, step up deepsea environmental management, understand the accumulative effects of human and climate on deep-sea creatures' diversity and ecological system's health, and strengthen controls targeting micro-plastics around global oceans, strive forward to establish a responsible community of marine ecological protection and marine environment governance, and push forward the establishment of a community of shared future that guarantees the sustainable development of oceans and human being.

\section{REFERENCES}

Ardron, J. A., Ruhl, H. A., and Jones, D. O. B. (2018). Incorporating transparency into the governance of deep-seabed mining in the Area beyond national jurisdiction. Mar. Policy 89, 58-66. doi: 10.1016/j.marpol.2017. 11.021

Arthur, C., Baker, J., and Bamford, H. (2009). Proceedings of the International Research Workshop on the Occurrence, Effects and Fate of Microplastic Marine Debris. Tacoma, WA: University of Washington Tacoma.
We should share development achievements, let observing systems play a key role in verifying data, make datadriven decisions to affect blue economy sectors, strengthen international communications in terms of technology, human talents and information, and, by jointly designing and producing science-based products through collaborative public/private partnerships (Government, University, Enterprise, and Society), provide members with a platform to share policies, markets and growth.

We should push forward the establishment of blue partnerships around the globe, make mutual efforts to foster the new driving force of blue economy, explore new markets, generate new growth, co-establish service platforms and provide an industrial service platform of achieving global blue economy development, connecting technologies and markets, and also linking enterprises with finance.

\section{AUTHOR CONTRIBUTIONS}

LW and ZP: national macro-economic control policies, scientific innovation of the marine industry, red line of marine ecology. CC, AN, TD, KH, PL, GM, JT, EO, AR, SP, and JP (AtlantOS contribution): blue economy for science-based products, use case analysis of science-based products, developing, sharing and using ocean observing system "best practices" are essential for blue growth. MB, LL, EE, and DA: promotion of the blue economy in deep ocean stewardship initiative. CM and YaY: marine micro plastics, impact and governance. KP: data analysis and information delivery support observing enterprises. WT and YiY: cases of widening space for blue economy, treatment and restoration projects. ZX: ecological restoration.

\section{FUNDING}

The work has received partial funding from the European Union's Horizon 2020 Research and Innovation Programme under grant agreement no. 633211 (AtlantOS).

\section{ACKNOWLEDGMENTS}

This study was completed by seven teams coordinated by LW. Lead authors were CC, CM, KP, LW, MB, WT, and ZX. Each team's lead authors coordinated their co-authors, AR, AN, DA, EO, EE, GM, JP, JT, KH, LL, PL, SP, TD, YiY, YaY, and ZP.

Australian Government (2012). Australia's Submission to the Rio+20 Compilation Document, Rio+20 United Nations Conference on Sustainable Development. Canberra: Australian Government.

Behnam, A. (2012). "Building a blue economy: strategy, opportunities and partnerships in the Seas of East Asia," in The East Asian Seas Congress 2012, Changwon.

Bernard, S., Kudela, R., and Velo-Suarez, L. (2014). "Chapter Eight: Developing global capabilities for the observation and prediction of harmful algal blooms," in Oceans and Society Blue Planet, eds S. Djavidnia, V. Cheung, M. Ott, 
and S. Seeyave (Newcastle upon Tyne: Cambridge Scholars Publishing), 46-53.

Bräger, S., Romero Rodriguez, G. Q., and Mulsow, S. (2018). The current status of environmental requirements for deep seabed mining issued by the International Seabed Authority. Marine Policy (in press). doi: 10.1016/j.marpol.2018. 09.003

China Research Intelligence Group (2018). The Assessment of Territory Space Development Suitability. Available at: https://wenku.baidu.com/view/ dd6ble622379168884868762caaedd3382c4b57f.html (accessed September 11, 2018).

China's search (2018). "Jiaolong" Explore the Sea: The World of the Deep Ocean is Beyond Your Imagination. Available at: http://baijiahao.baidu.com/s?id= $1600665570351702697 \& w f r=$ spider $\&$ for $=$ pc $($ accessed May 17, 2018).

Chinese State of Council (2014). Guiding Opinions on Relying on Golden Waterway to Promote the Development of Yangtze River Economic Zone. Beijing: Chinese State of Council.

Cole, M., Lindeque, P., Halsband, C., and Galloway, T. S. (2011). Microplastics as contaminants in the marine environment: a review. Mar. Pollut. Bull. 62, 2588-2597. doi: 10.1016/j.marpolbul.2011.09.025

Committee of the regions (2013). Blue Growth Opportunities for Marine and Maritime Sustainable Growth. Brussels: Committee of the regions.

Commonwealth Scientific and Industrial Research Organisation [CSIRO] (2008). Blue GDP: Ocean-Based Industrial Development and Growth. Canberra: Commonwealth Scientific and Industrial Research Organisation.

Cusack, C., Silke, J., Ruiz-Villarreal, M., Eikrem, W., Dale, T., Moejes, F., et al. (2018). Harmful Algal Bloom Bulletins. AtlantOS Deliverable, D8.6. Kiel: AtlantOS, 36.

Cuyvers, L., Berry, W., Gjerde, K. M., Thiele, T., and Wilhem, C. (2018). Deep Seabed Mining: A Rising Environmental Challenge. Gland: IUCN.

Dale, T., Cusack, C., and Ruiz, M. (2017). Aquaculture Site Selection Report. AtlantOS Deliverable, D8.2. Kiel: AtlantOS, 39.

Durden, J. M., Murphy, K., Jaeckel, A., Van Dover, C. L., Christiansen, S., Gjerde, K., et al. (2017). A procedural framework for robust environmental management of deep-sea, mining projects using a conceptual model. Mar. Policy 84, 193-201. doi: 10.1016/j.marpol.2017.07.002

Fang, T. (2016). Selected as One of the First Batch of Pilot Cities of "Blue Bay Regulation Action". Available at: http://qinhuangdao.jiwu.com/news/2587198. html (accessed August 18, 2016).

Gollner, S., Kaiser, S., Menzel, L., Jones, D. O., Brown, A., Mestre, N. C., et al. (2017). Resilience of benthic deep-sea fauna to mining activities. Mar. Environ. Res. 129, 76-101. doi: 10.1016/j.marenvres.2017.04.010

Grehan, A. J., Arnaud-Haond, S., D’Onghia, G., Savini, A., and Yesson, C. (2017). Towards ecosystem-based management and monitoring of the deep Mediterranean, North-East Atlantic and Beyond. Deep Sea Res. II 145, 1-7. doi: 10.1016/j.dsr2.2017.09.014

Guidetti, P., and Danovaro, R. (2017). Global ocean conservation under the magnifying glass. Aquat. Conserv. Mar. Freshw. Ecosyst. 28, 259-260. doi: 10.1002 /aqc. 2854

Häyhä, T., and Franzese, P. P. (2014). Ecosystem services assessment: a review under an ecological-economic and systems perspective. Ecol. Modell. 289, 124-132. doi: 10.1016/j.ecolmodel.2014.07.002

Hein, J. R., Mizell, K., and Barnard, P. L. (2013). Mineralogical compositions of sediment samples from the San Francisco Bay coastal system. Pharmacopsychiatry 46, 54-58. doi: 10.1594/PANGAEA.803903

Howard, B. C. (2018). Blue growth: stakeholder perspectives. Mar. Policy 87, 375-377. doi: 10.1016/j.marpol.2017.11.002

IOC/UNESCO, IMO, FAO, and UNDP. (2011). A Blueprint for Ocean and Coastal Sustainability. Paris: IOC/UNESCO.

Jambeck, J. R., Geyer, R., Wilcox, C., Siegler, T. R., Perryman, M., Andrady, A., et al. (2015). Plastic waste inputs from land into the ocean. Science 347, 768-771. doi: $10.1126 /$ science. 1260352

Jones, D. O. B., Kaiser, S., Sweetman, A. K., Smith, C. R., Menot, L., Vink, A., et al. (2017). Biological responses to disturbance from simulated deep-sea polymetallic nodule mining. PLoS One 12:e0171750. doi: 10.1371/journal.pone. 0171750

Jones, H. P., Jones, P. C., Barbier, E. B., Blackburn, R. C., Rey Benayas, J. M., Holl, K. D., et al. (2018). Restoration and repair of Earth's damaged ecosystems. Proc. Biol. Soc. 285:20172577.
Kathijotes, N. (2013). Keynote: blue economy - environmental and behavioural aspects towards sustainable coastal development. Procedia Soc. Behav. Sci. 101, 7-13. doi: 10.1016/j.sbspro.2013.07.173

Keen, M. R., Schwarz, A.-M., and Wini-Simeon, L. (2018). Towards defining the Blue Economy: practical lessons from pacific ocean governance. Mar. Policy 88, 333-341. doi: 10.1016/j.marpol.2017.03.002

Klinger, D., Eikeset, B., Davíðsdóttir, A., Winter, M., and Watson, J. (2018). The mechanics of blue growth: management of oceanic natural resource use with multiple, interacting sectors. Mar. Policy 87, 356-362. doi: 10.1016/j.marpol. 2017.09.025

Lehodey, P., Senina, I., Calmettes, B., and Titaud, O. (2017). Operational Real-Time and Forecast Modelling of Atlantic Albacore Tuna. AtlantOS Deliverable. Kiel: AtlantOS, 29.

Levin, L. A., Mengerink, K., Gjerde, K. M., Rowden, A. A., Van Dover, C. L., Clark, M. R., et al. (2016). Defining "Serious Harm" to the marine environment in the context of deep-seabed mining. Mar. Policy 74, 245-259. doi: 10.1016/j.marpol. 2016.09.032

Lillebø, A. I., Pita, C., Garcia Rodrigues, J., Ramos, S., and Villasante, S. (2017). How can marine ecosystem services support the blue growth agenda? Mar. Policy 81, 132-142. doi: 10.1016/j.marpol.2017.03.008

Lodge, M. W., and Verlaan, P. A. (2018). Deep-sea mining: international regulatory challenges and responses. Elements 14, 331-336. doi: 10.2138/gselements.14. 5.331

Lusty, P. A. J., and Murton, B. J. (2018). Deep-ocean mineral deposits: metal resources and windows into earth processes. Elements 14, 301-306. doi: 10. 2138/gselements.14.5.301

Mannarini, G., Pinardi, N., and Coppini, G. (2018). "Low carbon intensity routes via ocean currents and waves," in Technology and Science for the Ships of the Future, Proceedings of NAV 2018: 19th International Conference on Ship \& Maritime Research, eds A. Marinò and V. Bucci (Amsterdam: IOS Press BV), 340-347.

Mannarini, G., Pinardi, N., Coppini, G., Oddo, P., and Iafrati, A. (2016). VISIR-I: small vessels-least-time nautical routes using wave forecasts. Geosci. Model Dev. 9, 1597-1625. doi: 10.5194/gmd-9-1597-2016

McGlade, J., Werner, B., Young, M., Matlock, M., Jefferies, D., Sonnemann, G., et al. (2012). Measuring Water Use in a Green Economy, A Report of the Working Group on Water Efficiency to the International Resource Panel. Nairobi: UNEP.

Mengerink, K., Van Dover, C., Ardron, J., Baker, M., Escobar-Briones, E., Gjerde, K., et al. (2014). A call for deep-ocean stewardship. Science 344, 696-698. doi: $10.1126 /$ science. 1251458

Ministry of Ecology and Environment, The National Development and Reform Commission, and The Ministry of Natural Resources. (2018). Action Plan for the Struggle of Comprehensive Governance of the Bohai Sea. Beijing: Ministry of Ecology and Environment.

Mulazzani, L., Trevisi, R., Manrique, R., and Malorgio, G. (2016). Blue growth and the relationship between ecosystem services and human activities: the Salento artisanal fisheries case study. Ocean Coast. Manag. 134, 120-128. doi: 10.1016/ j.ocecoaman.2016.09.019

National Development and Reform Commission (2011). Development Planning of Blue Economic Zone in Shandong peninsula. Beijing: National Development and Reform Commission.

National Development and Reform Commission (2017). Some Opinions on Establishing a Long-term Mechanism for Monitoring and Early Warning of Resources and Environment Bearing Capacity. Beijing: National Development and Reform Commission.

Neves, A. A. S., Pinardi, N., Martins, F., Janeiro, J., and Cesarini, C. (2018). Oil Spill Hazard Bulletin. Kiel: AtlantOS.

Pauli, G. (2009). The Blue Economy_-A Report to the Club of Rome. Nairobi: UNEP.

People's Daily (2018). Laizhou, shandong: Regulate the Pollution Into the Sea, and Take Care of the Bohai Sea. Available at: http://sd.chinaso.com/sy/detail/ 20180825/1000200033118911535154219337365612_1.html. (accessed August $25,2018)$.

Qingdao Municipal Government (2012). Qingdao Blue Silicon Valley Planning. Qingdao: Qingdao Municipal Government.

Ramirez-Llodra, E., Tyler, P. A., Baker, M. C., Bergstad, O. A., Clark, M. R., Escobar, E., et al. (2011). Man and the last great wilderness: human impact on the deep sea. PLoS One 6:e22588. doi: 10.1371/journal.pone.0022588 
Raubenheimer, K., and McIlgorm, A. (2018). Can the basel and stockholm conventions provide a global framework to reduce the impact of marine plastic litter? Mar. Policy 96, 285-290. doi: 10.1016/j.marpol.2018.01.013

Rio+20 Pacific Preparatory Meeting (2011). The "Blue Economy": A Pacific Small Island Developing States Perspective Apia, Samoa. Apia: Rio+20 Pacific Preparatory Meeting.

Sarker, S., Bhuyan, M. A. H., and Rahman, M. M. (2018). From science to action: exploring the potentials of Blue Economy for enhancing economic sustainability in Bangladesh. Ocean Coast. Manag. 157, 180-192. doi: 10.1016/ j.ocecoaman.2018.03.001

Science 24 hours (2016). Snow Dragon's Polar Exploration. Available at: https: //www.cdstm.cn/gallery/media/mkjx/kx24xs/201705/t20170505_484413.html (accessed July 01, 2016).

Soma, K., van den Burg, S. W. K., Hoefnagel, E. W. J., Stuiver, M., and van der Heide, C. M. (2018). Social innovation - a future pathway for blue growth? Mar. Policy 87, 363-370. doi: 10.1016/j.marpol.2017.10.008

State Oceanic Administration of China (2015). Implementing Scheme of Marine Ecological Civilization Construction (2015-2020). Beijing: State Oceanic Administration of China.

Tilot, V., Ormond, R., Moreno Navas, J., and Catalá, T. S. (2018). The benthic megafaunal assemblages of the CCZ (eastern pacific) and an approach to their management in the face of threatened anthropogenic impacts. Front. Mar. 5:7. doi: 10.3389/fmars.2018.00007

Tinker, J., Krijnen, J., Wood, R., Barciela, R., and Dye, S. R. (2018). What are the prospects for seasonal prediction of the marine environment of the Northwest European shelf? Ocean Sci. 14, 887-909. doi: 10.5194/os-14-887-2018

Tunnicliffe, V., Metaxas, A., Le, J., Ramirez-Llodra, E., and Levin, L. A. (2018). Strategic environmental goals and objectives: setting the basis for environmental regulation of deep seabed mining. Mar. Policy (in press). doi: 10.1016/j.marpol.2018.11.010

UNEP, FAO, IMO, UNDP, IUCN, World Fish Center, et al. (2012). Green Economy in a Blue World. Nairobi: UNEP.

van den Burg, S. W. K., Aguilar-Manjarrez, J., Jenness, J., and Torrie, M. (2019). Assessment of the geographical potential for co-use of marine space, based on operational boundaries for Blue Growth sectors. Mar. Policy 100, 43-57. doi: 10.1016/j.dib.2018.11.118
Van Nijen, K., Passela, S. V., and Squires, D. (2018). A stochastic techno-economic assessment of seabed mining of polymetallic nodules in the Clarion Clipperton Fracture Zone. Mar. Policy 95, 133-141. doi: 10.1016/j.marpol.2018.02.027

Vanreusel, A., Hiliario, A., Ribeiro, P. A., Menot, L., and Arbizu Martinez, P. (2016). Threatened by mining, polymetallic nodules are required to preserve abyssal epifauna. Sci. Rep. 6:26808. doi: 10.1038/srep26808

Vince, J., and Hardesty, B. D. (2017). Plastic pollution challenges in marine and coastal environments: from local to global governance. Restor. Ecol. 25, 123-128. doi: 10.1111/rec.12388

Volkmann, S. E., Kuhn, T., and Lehnen, F. (2018). A comprehensive approach for a techno-economic assessment of nodule mining in the deep sea. Miner. Econ. 31, 319-336. doi: 10.1007/s13563-018-0143-1

Voyer, M., Quirk, G., McIlgorm, A., and Azmi, K. (2018). Shades of blue: what do competing interpretations of the Blue Economy mean for oceans governance? J. Environ. Policy Plann. 20, 595-616. doi: 10.1080/1523908x.2018.147 3153

Voyer, M., and van Leeuwen, J. (2019). 'Social license to operate' in the Blue Economy. Resour. Policy 62, 102-113. doi: 10.1016/j.resourpol.2019.02.020

Williams, J., Horsburgh, K. J., Williams, J. A., and Proctor, R. N. F. (2016). Tide and skew surge independence: new insights for flood risk. Geophys. Res. Lett. 43, 6410-6417. doi: 10.1002/2016gl069522

Yu, H., Liang, D., Tan, Q., and Li, J. (2018). Marine waste and microplastic pollution and its international process. World Environ. 2, 50-53.

Conflict of Interest Statement: The authors declare that the research was conducted in the absence of any commercial or financial relationships that could be construed as a potential conflict of interest.

Copyright (C) 2019 Wenhai, Cusack, Baker, Tao, Mingbao, Paige, Xiaofan, Levin, Escobar, Amon, Yue, Reitz, Neves, O'Rourke, Mannarini, Pearlman, Tinker, Horsburgh, Lehodey, Pouliquen, Dale, Peng and Yufeng. This is an open-access article distributed under the terms of the Creative Commons Attribution License (CC BY). The use, distribution or reproduction in other forums is permitted, provided the original author(s) and the copyright owner(s) are credited and that the original publication in this journal is cited, in accordance with accepted academic practice. No use, distribution or reproduction is permitted which does not comply with these terms. 